\title{
Interactive comment on "A typical weather pattern for the ozone pollution events in North China" by Cheng Gong and Hong Liao
}

\section{Anonymous Referee \#2}

Received and published: 22 July 2019

General comments: Ozone pollution in China is becoming a noticeable problem particularly in summer season. This paper focuses on this problem in north China region. Two parts of work have done. One is a long term (4 years) analysis of the ozone pollution status. Ozone pollution days and events are defined and identified in the research years. Using these days/events, the so called correspondent weather pattern are composited. The second part of work is to establish an index to identify the ozone pollution day/event. Using GEOS-Chem model, simulation results for these 4 summers are used to support the index.

The ozone pollution status is clearly shown. The related weather pattern seems a reasonable but anticipative result. The GEOS-Chem simulation provides results not so informative. 
Specific comments: 1)It is well known that the ozone pollution is related to sunny days, high temperature, precursors, boundary layer process, etc. Once the high ozone events are selected, the statistics of weather pattern is just a conditional sampling result, so that the features are anticipative.

2)The selection of Index_U500 seems quite arbitrary. What does it mean by the wind speed difference of two zones? What is the reason to choose these two zones? Is it ok the zones larger or smaller?

3)GEOS-Chem simulation of ozone concentration does not agree to the observation satisfactorily in Figure 8.

4)The role of diffusion or mixing on ozone mass flux is not clearly described. At first, the authors declare "Note that the MF of each process at a specific level indicates the net $\mathrm{O} 3$ mass change within this level rather than the flux across this level, especially for the vertical processes such as diffusion and vertical advection", but at later, they state "it is indicated that $\mathrm{O} 3$ aloft is transported downward to be mixed at the surface by the diffusion process", and "Vertical advection exhibits negative MF values from the surface to approximately $750 \mathrm{hPa}$ ". We need to clarify it is the "mass flux" or the "mass flux divergence", the former indicates mass across the level, the latter is the net mass change.

5)I think the ozone production is mainly within the atmospheric boundary layer, not above it. So it is not true: "hot air is beneficial for developing the mixed layer, leading to more $\mathrm{O} 3$ mixed downward to the surface during OPEs".

Other points:

0) too many acronym, someone not necessary, for example, mass flux: MF. 1)Page 1 line19: "chemical production of $\mathrm{O} 3$ was high between 800 and $900 \mathrm{hPa",} \mathrm{what} \mathrm{height?}$ 2)Page 3, line 22: "Section 3 presents the observed and spatiotemporal distributions of OPEs in North China during 2014 to 2017", sentence not very clear. 3)page 3: 
(http://datacenter.mep.gov.cn/websjzx/querylndex.vm), no linkage. 4)page 4, line 2: "(67 sites among the 114 sites in North China (36ïĆř-40.5ïĆřN, 114.5ïĆř-119.5ïĆřE)) are selected and used in this study." Need more details or figure to show the 67 sites. 5)Page 4, line 20: "MERRA2 dataset, daily mean geopotential heights at $850 \mathrm{hPa}$ and $500 \mathrm{hPa}$ from the National Center for Environmental Prediction (NCEP)...", MERRA2 and NCEP dataset, consistent? At least the resolution is different. 6)page 4, line 24: "All the time series of meteorological parameters have been detrended first and then standardized by their respective standard deviation to remove interannual or seasonal variability", what is the performance and result? 7)page 6 line 1: "all 62 sites", previously 67 sites! 8)page 6 , line 24: "last for many consecutive days. The mean duration of OPEs is 4.3 days, while some episodes can last for one week and even Longer". Can be interpreted by sub-tropical high, in summer. 9)page 8 line 10: " $850 \mathrm{hPa}$ zonal winds indicate circulation in the lower atmosphere and $500 \mathrm{hPa}$ meridional winds describe the dominate large-scale circulation", why take zonal winds at $850 \mathrm{hPa}$ ? 10)Figure 5: why the calculation region for $\mathrm{V} \_850 \mathrm{hPa}$ differently? 11)Figure 7 , similar to Figure 4 ? 12)Page 9 line 21: "indicating that the GEOS-Chem model can simulate the daily variation in MDA8 O3", but the simulation not agree well to the observation in Figure 8. 13)page 9 line 26: " The linear regression through the origin between observed and simulated MDA8 03 has a regression coefficient of 0.96 , indicating the capability of the model in simulating the MDA8 O3 concentrations." Need to be clarified. 14)page 10, line 29: "diffusion has a small effect on the total mass of $\mathrm{O} 3$ in the boundary layer. However, the diffusion process is important in 30 the boundary layer, which has...", confused. 15)page 10 line 31: "mass flux of diffusion for the whole boundary layer is small, it is indicated that $\mathrm{O} 3$ aloft is transported downward to be mixed at the surface by the diffusion process", very strange explanation. 16)Page 11 line 13: "both the positive contribution at the surface and the negative contributions in the upper layers increase", ok. "indicating that more $\mathrm{O} 3$ is mixed from the upper levels to the surface to increase the surface $\mathrm{O} 3$ concentration during OPEs", why mixing/diffusion increase surface $\mathrm{O} 3$ ? 17)Page 12 line 1: "beneficial for developing the mixed layer, leading to more $\bigcirc 3$ mixed

Interactive comment
Printer-friendly version

Discussion paper 
downward to the surface during OPEs", O3 produces in the boundary layer, no need to mixing down from upper layer above ABL. 18)page 13 line 14: "horizontal advection, and vertical advection are the most dominant processes that lead to OPEs", but horizontal advection contributes negative mass flux? So, not lead to OPEs, but depress the development of OPEs.

Interactive comment on Atmos. Chem. Phys. Discuss., https://doi.org/10.5194/acp-2019-263, 2019. 